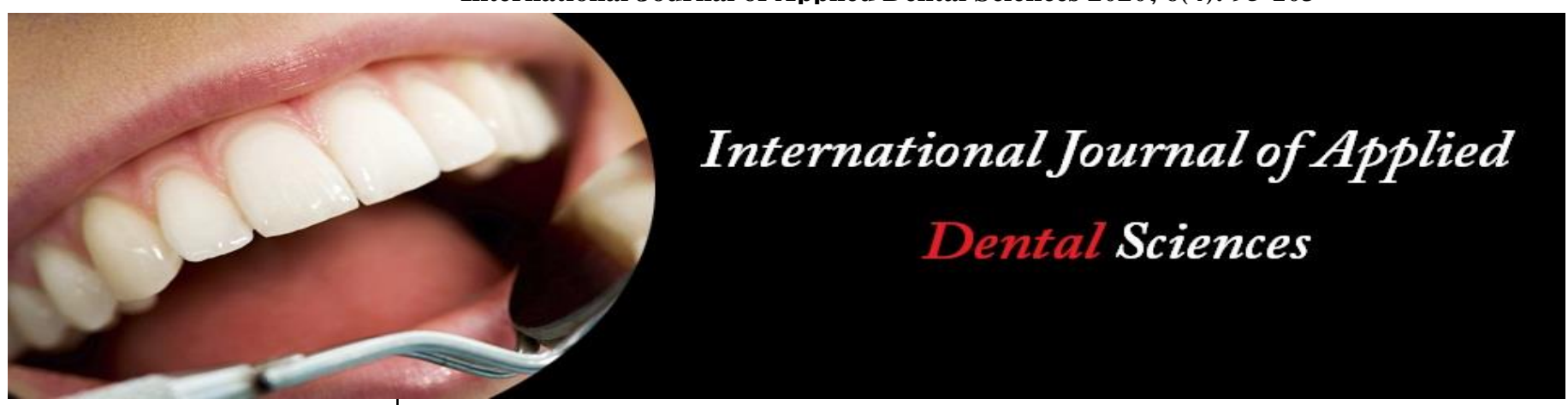

ISSN Print: 2394-7489

ISSN Online: 2394-7497

IJADS 2020; 6(4): 95-103

(C) 2020 IJADS

www.oraljournal.com

Received: 19-08-2020

Accepted: 23-09-2020

Dr. Deepti Rao M

MDS, Department of

Conservative and Endodontics Consultant Endodontist, Tooth

Fairy Dental Clinic Rd No 10,

Banjara Hills, Hyderabad,

Telangana, India

Dr. R Nageswar Rao

Professor and Past HOD,

Department of Conservative and

Endodontics, SDM Dental

College and Hospital, Sattur,

Dharwad, Karnataka, India

Corresponding Author:

Dr. Deepti Rao M

MDS, Department of

Conservative and Endodontics

Consultant Endodontist, Tooth

Fairy Dental Clinic Rd No 10,

Banjara Hills, Hyderabad,

Telangana, India

\section{Microtensile bond strength of Resin composite to Normal dentin and Caries - affected dentin with total- etch and self-etch bonding adhesives before and after thermocycling}

\author{
Dr. Deepti Rao M and Dr. R Nageswar Rao
}

DOI: $\underline{\text { https://doi.org/10.22271/oral.2020.v6.i4b.1053 }}$

\section{Abstract}

Objectives: To measure the microtensile bond strength of total-etch and self-etch adhesives to intact and caries affected dentin. To check the effect of thermal cycling on the bond strength of these adhesives to caries affected and intact dentin.

Materials and Methods: Thirty extracted carious human molars were assigned to two groups according to adhesive used i.e Adper Single Bond (Total etch) with P90 (Self-etch). The occlusal surface of teeth will be sectioned to expose dentin and built up with Filtek 90 composite (3M) to a $3 \mathrm{~mm}$ height. The teeth were then sectioned to obtain rods of $6 \mathrm{~mm}$ length and $1 \mathrm{~mm}$ width and $1 \mathrm{~mm}$ depth with dentincomposite interface located at the centre. The specimens were examined under microscope to separate caries-affected dentin and unaffected dentin into two groups. Half the specimens from each group were subjected to 3000 thermo cycles (5 deg Celsius to $55 \mathrm{deg}$ Celsius). All specimens were subjected to microtensile bond strength testing in a special apparatus attached to the Universal testing machine. Results were recorded and data was statistically analyzed with Students unpaired ' $t$ 'test.

Results: Students ' $t$ 'test showed that the values had a statistically significant difference observed between total etch (T.E) i.e. Adper Single Bond 2 and self etch (S.E) i.e. P 90; caries-affected dentin (CAD) and normal dentin (ND); with thermocycling and without thermocycling.

Interpretation and Conclusion: The present study concludes that total-etch has a higher bond strength compared to self-etch. Bond strengths are higher to normal dentin than caries-affected dentin. Thermocycling lowers the bond strength values of all the groups.

Keywords: Caries-affected dentin, normal dentin, Microtensile bond strength, total-etch dentin bonding agent, self-etch dentin bonding agent, thermocycling

\section{Introduction}

The increasing demand for esthetic restorations has generated intensive research of adhesive materials. Successful adhesion to dental hard tissues is a fundamental requirement prior to the insertion of resin - based composites ${ }^{[1]}$. Dentin adhesives are widely used in clinical dentistry and improved or new versions are being constantly introduced which are claiming to offer advantages over their predecessors ${ }^{[2]}$.

Since Buonocore, a number of new adhesive systems have been developed in an attempt to reduce the steps \& simplify clinical bonding procedures ${ }^{[3]}$. One approach employs the totaletching technique, which simultaneously removes the smear layer from both enamel $\&$ dentin surfaces, followed by application of a 1 - bottle primer $\&$ adhesive. As demineralised collagen fibril mesh is used as the bonding substrate, a wet bonding technique is required to ensure its full expansion. The need for a moist dentine surface in complex cavity preparations often create overwet and underwet regions in the same tooth, making bonding to dentin with these adhesives very technique sensitive.

The second approach is use of self-etching primers. Bonding mechanism is based on simultaneous etching \& priming of the smear covered dentin using an acidic primer followed by application of an adhesive resin. These eliminate separate acid etching \& rinsing steps \& simplify bonding as the problem of over drying or over- wetting the dentin is eliminated. 
This reduces the potential for post-operative sensitivity \& bonding problems associated with movement of dentinal fluid through patent dentinal tubules. The technique sensitivity associated with bonding to a dehydrated collagen matrix is also eliminated. These systems also provide a faster application due to reduced number of components and application steps ${ }^{[4]}$.

Bonding to enamel is primarily based upon mechanical interlocking of the bonding resin with the created micropores on the enamel surface. Bonding to dentin is more complex due to inherent characteristics \& morphological features of dentin with different chemical \& histological composition. Dentin has tubules running through it, carrying dentinal fluid from the pulp. This causes bonding process to be more challenging \& unlike enamel, a primer is always necessary when bonding to dentin to form the hybrid layer ${ }^{[3]}$.

The development of recent adhesive restorative materials has brought about changes in the philosophies of cavity preparation. These have been replaced by more conservative techniques with removal of only infected, permanently damaged carious tissue. But the bacteria-free, caries-affected dentin / sclerotic dentin are preserved and disease progression is prevented. Most adhesion studies are performed on normal dentin, although clinically, most substrates are not normal dentin. Clinicians must deal with variants like caries-affected dentin, cervical sclerotic dentin or even intrinsic differences between coronal \& radicular dentin.

Several other factors are known to effect the tensile bond strength of dentin bonding agents such as long term storage, thermal stress, tooth flexure, simulated pulpal pressure, dentin substrate variations \& 3- dimensional cavity preparation to name a few ${ }^{[6]}$. Also the occlusal forces applied to a restoration may be complex \& made up of a combination of forces such as shear, tension, compression \& flexure with tensile stresses being the most common. Marginal percolation is initiated, in part, by the difference in the coefficient of thermal expansion of the tooth and the restoration and by the thermal expansion of fluids occupying the tooth/restoration interface. (Nelsen et al.) Hence to study these effects thermocycling is done in the present study. The efficiency of these simplified bonding systems is controversial and practically all published reports have used normal dentin as bonding substrate. However, most clinical adhesive procedures involve altered forms of dentin ${ }^{[4]}$.

Conventional testing methodologies are not applicable to such clinically relevant substrates due to the limited size \& irregular shape of abnormal dentin ${ }^{[5]}$. Accordingly, it follows that no single test can satisfactorily predict the intraoral behaviour of an adhesive system. Adhesion analysis of dentin bonding agents has been performed by numerous mechanical testing methods including shear bond strength, tensile bond strength, microleakage \& contraction gap size measurements. Agreement on test standardization is complicated by the enormous number of test variables involved \& the variable nature of the heterogeneous dentin ${ }^{[6]}$. The development of microtensile test method, that utilizes specimen crosssectional areas of approximately $1 \mathrm{~mm}^{2}$, has allowed the determination of bond strengths of several bonding systems to caries-affected dentin ${ }^{[3]}$.

Thus this study aims to determine the microtensile bond strength of caries-affected and normal dentin using total-etch $\&$ self-etch adhesives before and after thermocycling. This may provide an added insight into understanding the essentials of the fundamental mechanism of adhesion of polymeric biomaterials to dentin.

\subsection{Objectives}

1. To measure the microtensile bond strength of totaletch and self-etch adhesives to intact and caries affected dentin.

2. To compare the bond strengths to caries-affected and normal dentin

3. To check the effect of thermal cycling on the bond strength of these adhesives to caries affected and intact dentin.

\section{Materials and Methodology}

2.1 Sample Selection: This study utilised freshly extracted human molars $(\mathrm{n}=30)$ previously stored in $3 \%$ chloramines solutions. All teeth had Class 1 occlusal caries, and were not pulpally involved. (Fig $1 \mathrm{~A}, \mathrm{~B})$ The crown portions were horizontally sectioned at a level $1 \mathrm{~mm}$ below the dentinoenamel junction using the slow speed diamond disc with intermediate water cooling to expose the flat dentinal surface. Both carious \& normal dentin was present on the same surface. The exposed dentin surfaces were examined visually and their surface texture was tested with a spoon excavator. Surfaces with soft, discoloured dentin were considered cariesinfected and were exclude ed. Hard, brown dentin was considered as caries-affected, while light-yellow dentin was considered to be sound. Dentin surfaces were further examined using a light microscope to eliminate specimens having either enamel or pulp tissues.
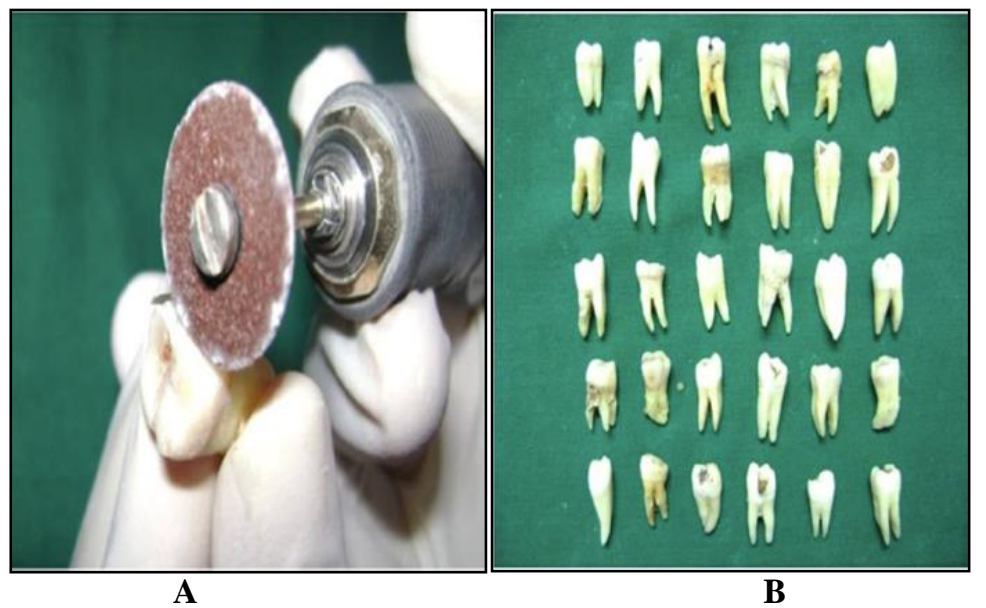

Fig 1: (A) Thirty molars with occlusal caries not involving the pulp were used. (B) the crown was sectioned at the level of the DEJ to expose parts of Normal Dentin (ND) and Caries Affected Dentin (CAD) 
2.2 Grouping of Samples: The selected teeth were randomly divided into 2 groups of 15 teeth each (Fig 2), according to bonding agent used i.e.

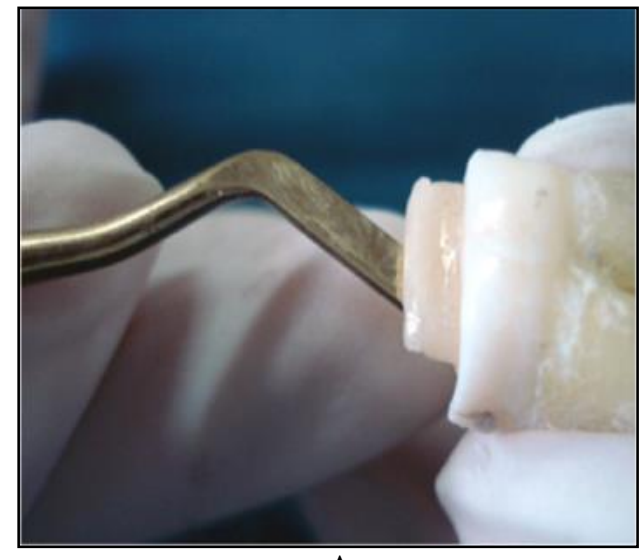

A
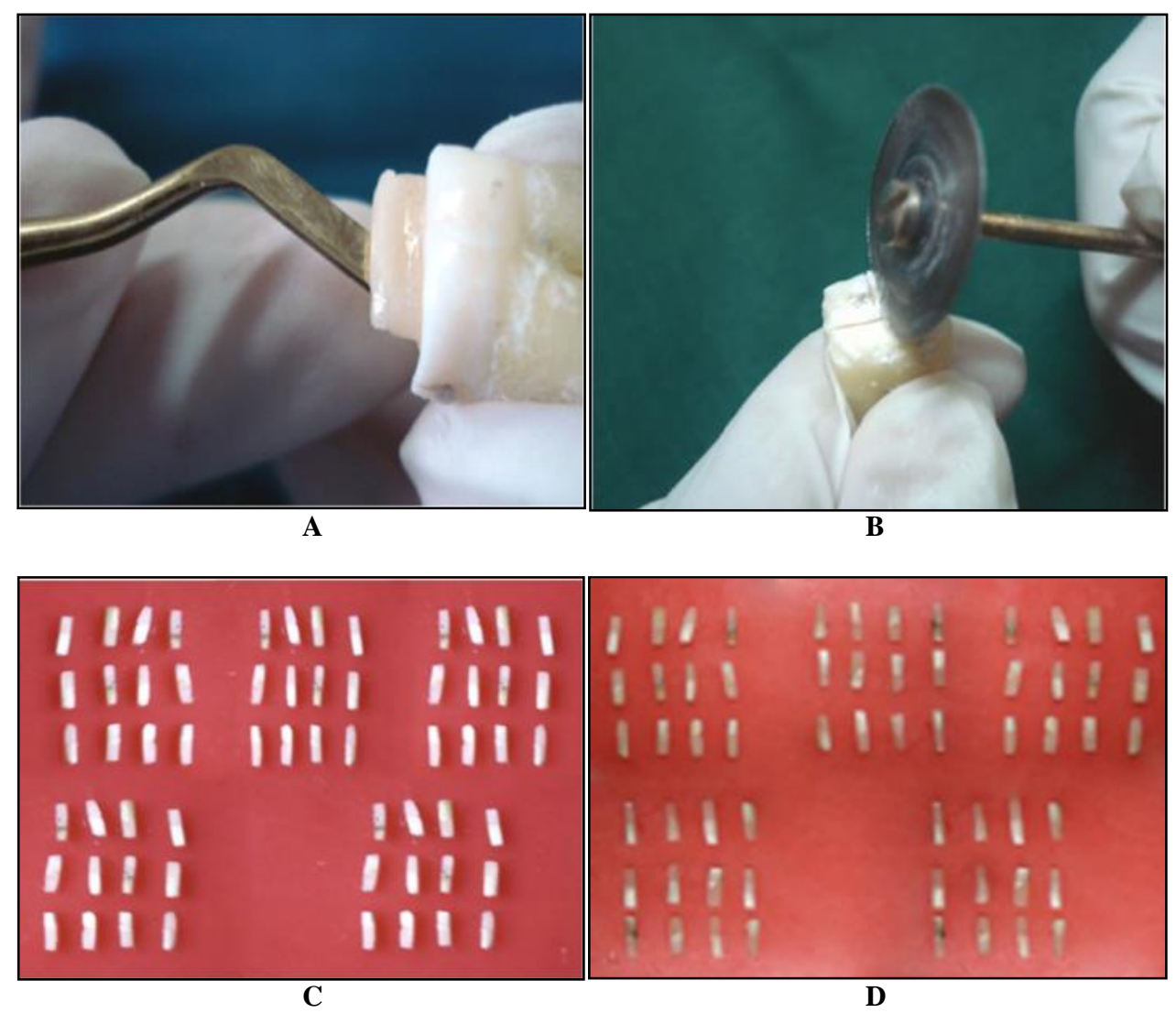

Fig 2: (A) Composite resin build-up done to achieve a height of $3 \mathrm{~mm}$ incrementally. (B) Sectioning done to achieve sections of W $1 \mathrm{~mm} x \mathrm{~B}$ $1 \mathrm{~mm}$ x H 6mm using a sectioning disc. (C) Group 1- Sections obtained from Adper Single Bond 2. (D) Group 2 - Sections obtained from P90 bonding agent

Group I- Total-etch group ( $\mathrm{n}=15$ teeth);

Group II- Self-etch group ( $\mathrm{n}=15$ teeth)

\subsection{Bonding of Samples}

The flat dentinal surfaces of each group of teeth were then built up with composite resin, after application of the respective dentin bonding agents. The adhesives were applied according to manufacturer's instructions. For Group I, 15 teeth were bonded using a 2-step total-etch bonding agent, Adper Single Bond 2 (3M ESPE, St Paul, MN, USA). Firstly, an etchant was applied to enamel \& dentin. After an interval of 15 seconds, the surface was rinsed with water for 10 seconds. Excess water was blotted using a cotton pellet. The criteria for dryness were considered that the surface should appear glistening without pooling of water.

Table 1: Grouping of Sections

\begin{tabular}{|c|c|c|c|}
\hline & Groups & Subgroup A & Subgroup B \\
\hline \multirow[b]{2}{*}{ Group I } & \multirow{2}{*}{$\begin{array}{l}\text { Total Etch Dentin Bonding Agent } \\
\text { (T.E) ( } n=60 \text { Samples) }\end{array}$} & $\begin{array}{c}\text { Caries-Affected Dentin (CAD) } \\
\text { (Group I } n=30 \text { Samples Group II } n=30 \text { Samples) }\end{array}$ & $\begin{array}{c}\text { Normal Dentin (ND) } \\
\text { (Group I } n=30 \text { Samples Group II } n=30 \text { Samples) }\end{array}$ \\
\hline & & $\begin{array}{c}\text { With Thermocycling } \\
\text { (Group I } \mathrm{n}=15 \text { Group II } \mathrm{n}=15)\end{array}$ & $\begin{array}{c}\text { With Thermocycling } \\
\text { (Group I } n=15 \text { Group II } n=15)\end{array}$ \\
\hline Group II & $\begin{array}{l}\text { Self-Etch Dentin Bonding Agent } \\
\text { (S.E) (n=60 Samples) }\end{array}$ & $\begin{array}{l}\text { Without Thermocycling } \\
\text { (Group I } n=15 \text { Group II } n=15 \text { ) }\end{array}$ & $\begin{array}{l}\text { Without Thermocycling } \\
\text { (Group I } n=15 \text { Group II n=15) }\end{array}$ \\
\hline
\end{tabular}

Immediately after blotting, 2-3 consecutive coats of adhesive was applied for 15 seconds, gently with a saturated applicator brush. It was gently air thinned for 5 seconds and light cured for 10 seconds using a quartz halogen light curing device. A universal restorative composite, Filtek Z350 (3M ESPE) A 3 shade was used for core build-up. It was built incrementally to form a bulk of composite of $3 \mathrm{~mm}$ height using Teflon coated cement spatulas and light-cured for 20 seconds each.

For Group II, 15 teeth were bonded using a 2-step selfetching dentin bonding agent, P90 System Adhesive (3M ESPE, St Paul, MN, USA). This system consists of a selfetching primer and bond in dosing bottles. Primer was applied to the entire surface with an applicator tip, in a massaging action for 15 seconds over the entire area and air dried gently. It was then light cured for 10 seconds.

Similarly, the Bond (adhesive) was applied. After bonding, immediately the surface was built- up using Filtek P90 (3M ESPE), a posterior, radiopaque, shrink free, silorane-based composite. A composite core of $3 \mathrm{~mm}$ was built incrementall and light cured for $20 \mathrm{sec}$ each. Filtek P90 \& P90 System Adhesive was used only in combination with one another as per the manufacturer's instructions.

\subsection{Sectioning}

These teeth were then stored at 37 degrees $\mathrm{C}$ for 24 hours in distilled water. They were then sectioned with a diamond disc 
to obtain specimens, each of $1 \mathrm{~mm}$ thickness and $6 \mathrm{~mm}$ length. (Fig 2 A,B) The sections were left attached to the remainder of the tooth for further sectioning to obtain rods $6 \mathrm{~mm}$ long and $1 \times 1 \mathrm{~mm}$ in thickness with dentin-composite interface located at the centre. The specimens were smoothened using the Arkansas stone. This also helped in achieving the required dimensions. The dimensions were measured with the help of a screw gauge. In each group (Group I $=15$ teeth; Group II $=15$ teeth), each tooth was sectioned to obtain 4 specimens per tooth on an average. Hence, each group consisted of 60 rods for each bonding agent i.e. (Group I $=60$ rods; Group II $=60$ rods) (Fig $2 \mathrm{C}, \mathrm{D})$. The specimens were then examined under a light microscope using $40 \mathrm{x}$ magnifications to separate caries-affected dentin and normal dentin. It was divided into two equal subgroups $(n=30)$ depending upon whether it was normal dentin (ND) or caries-affected dentin (CAD). Half the specimens from each subgroup group $(n=15)$ were subjected to thermocycling.

\subsection{Thermocycling}

Thermocycling was performed in the Mechanical Engineering Department at the S.D.M Engineering College, Dharwad. The apparatus for thermocycling consisted of 2 water baths (Fig 3 A, B, C, D) which were maintained at two specific temperatures ranging from hot to cold. One water bath was maintained at 5 degree Celsius, by constant addition of ice cubes and the other water bath was maintained at 55 degree Celsius, by using a heating apparatus connected to a thermostat. Both had a thermometer inserted into the respective baths and the change in temperature was manually controlled to maintain the required temperatures. Half of the sections from each of the 4 subgroups i.e. $(n=15)$ were separately tied in gauze pieces and placed in each bath, with a dwell time of 30 seconds and a 10 second transfer period between the two baths. A stopwatch was used so as not to exceed the time limit. This was done for 3000 cycles manually.

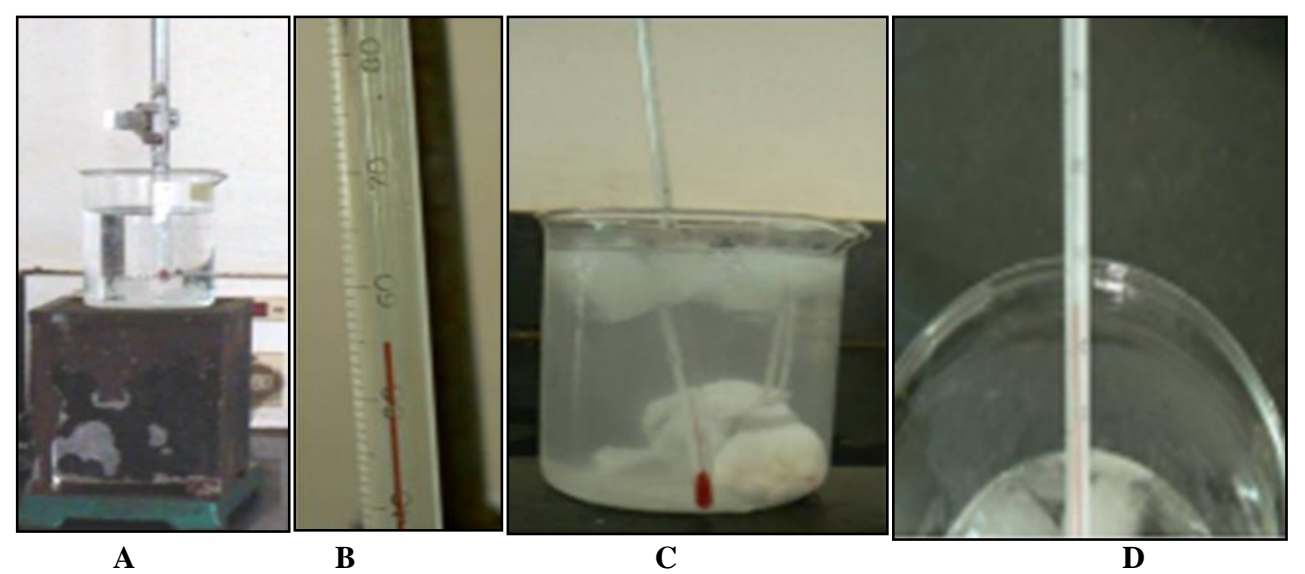

Fig 3: Thermocycling apparatus assembled and being carried out in (A) Beaker of water on a heating apparatus connected to a thermostat. B: thermometer shows a temperature of 55 Deg $\mathrm{C}$ achieved and maintained. (C) Beaker filled with ice and a thermometer inserted to check the temperature acheived: Thermometer shows temperature of $5 \mathrm{Deg} \mathrm{C}$ achieved.

2.6 Microtensile Testing: All the specimens $(n=120)$ then were loaded onto a jig (Custom-made at Nettur Technology \& Tools Fabricators (NTTF)) (Fig 4A) and underwent the microtensile testing using the Universal testing machine (Instron) (BISCO Inc, Schaumburg, IL, USA) (Fig 4B). Each specimen was glued to the jig using adhesive, Fevi Quick and left for 2 minutes to dry. These were then mounted onto the
Universal testing machine. Tensile load was applied until specimen failure at a speed of $1 \mathrm{~mm}$ per minute. Maximum load applied and failure load was recorded for each specimen and the microtensile bond strength was calculated. Means and standard deviations were determined for each group and data were statistically analyzed using students $\mathrm{t}$ - test.

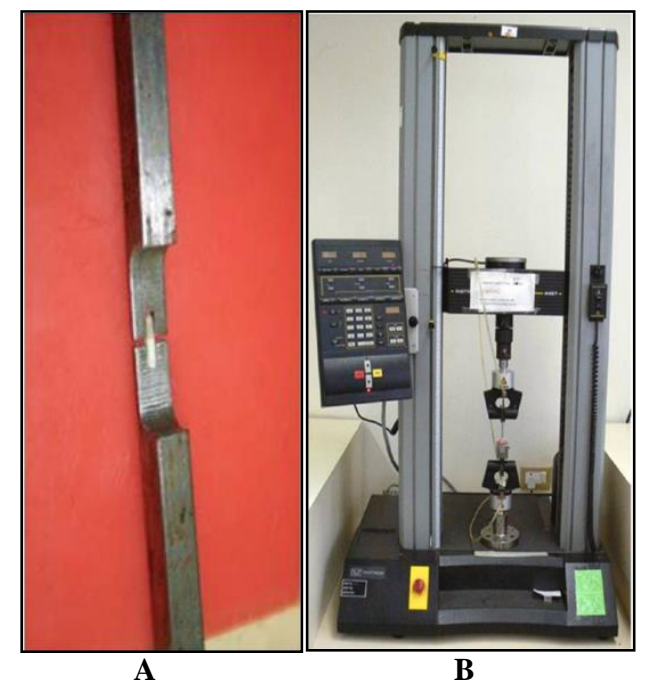

Fig 4: (A) An apparatus jig to position the Dentin-Composite resin section was custom designed and milled. It had a slot to fit the sample size of $1 \mathrm{~mm} \times 1 \mathrm{~mm} \times 6 \mathrm{~mm}$. Length of the jig was made of an arbitrary 5inches to fit into the Instron. (B) Universal Testing Machine, Instron which allows the jig to be placed and gives a digital recording of the value of at which the bond fracture takes place. 


\section{Results}

On bond strength testing, the maximum load at which the failure at the resin-dentin interface occurred was recorded digitally. The values obtained were in kiloforce $/ \mathrm{mm}^{2}$ and were then converted into Mega Pascals. The values were arranged in tabular columns and subject to Blom's proportional estimation formula to check the normal distribution parameters. Since, all the values were found within the normal distribution, a Students ' $t$ ' test was done for statistical analysis.
In our study, (Refer Table 2) the values obtained by Adper Single Bond 2 (Total Etch) for ND with thermocycling were $25 \mathrm{MPa}$, whereas without thermocycling it was $28 \mathrm{MPa}$. For $\mathrm{CAD}$, it showed bond strengths of $17 \mathrm{MPa}$ with thermocycling and $20 \mathrm{MPa}$ without thermocycling $(\mathrm{p}=0.000)$. With P90 (Self-etch), ND showed bond strengths of $15 \mathrm{MPa}$ with thermocycling and $18 \mathrm{MPa}$ without thermocycling. For $\mathrm{CAD}$, in the same group, with thermocycling a value of 12 MPa was obtained whereas without thermocycling, the bond strength achieved was 15 Mpa mean value $(\mathrm{p}=0.000)$.

Table 2: Results of Maximum Loading on the Sample expressed in MPa

\begin{tabular}{|c|c|c|c|c|c|c|c|}
\hline \multicolumn{4}{|c|}{ Group A - Total - Etch } & \multicolumn{4}{|c|}{ Group B - Self-Etch } \\
\hline \multicolumn{2}{|c|}{ N.D } & \multicolumn{2}{|c|}{ CAD } & \multicolumn{2}{|c|}{ N.D } & \multirow{2}{*}{\multicolumn{2}{|c|}{$\begin{array}{c}\text { CAD } \\
\text { W.O }(n=15) \\
\end{array}$}} \\
\hline W.T $(n=15)$ & W.O $(n=15)$ & W.T (n=15) & W.O $(n=15)$ & W.O $(n=15)$ & W.T (n=15) & & \\
\hline 31.1 & 30.7 & 18.8 & 17.9 & 14.1 & 18.4 & 12.2 & 16.6 \\
\hline 25.4 & 26.8 & 20.9 & 15.8 & 16.1 & 13.7 & 15.0 & 13.9 \\
\hline 25.1 & 23.8 & 19.5 & 18.5 & 10.3 & 13.8 & 10.5 & 17.1 \\
\hline 25.2 & 27.8 & 17.6 & 19.7 & 13.2 & 18.2 & 11.1 & 16.4 \\
\hline 24.7 & 27.5 & 16.9 & 17.8 & 8.9 & 15.4 & 10.2 & 15.4 \\
\hline 25.2 & 25.6 & 15.9 & 18.3 & 12.4 & 14.9 & 11.5 & 15.5 \\
\hline 25.5 & 34.1 & 17.8 & 20.7 & 13.2 & 15.6 & 11.3 & 18.4 \\
\hline 24.8 & 32.2 & 15.9 & 21.8 & 15.1 & 17.4 & 11.9 & 18.9 \\
\hline 26.3 & 25.8 & 15.5 & 24.6 & 11.4 & 13.7 & 11.3 & 16.4 \\
\hline 23.9 & 26.8 & 16.4 & 21.8 & 12.2 & 16.7 & 8.7 & 13.6 \\
\hline 25.2 & 28.5 & 14.7 & 22.6 & 10.6 & 16.3 & 8.5 & 14.8 \\
\hline 24.7 & 33.1 & 17.3 & 22.6 & 11.7 & 15.6 & 12.4 & 15.3 \\
\hline 21.9 & 27.5 & 16.9 & 22.8 & 8.7 & 13.9 & 10.3 & 18.1 \\
\hline 25.7 & 29.4 & 17.6 & 20.4 & 12.1 & 16.7 & 11.1 & 16.7 \\
\hline 24.8 & 33.2 & 15.8 & 23.1 & 10.6 & 18.9 & 9.1 & 17.3 \\
\hline
\end{tabular}

3.1 Statistical Analysis: Students ' $t$ ' test showed that the values had a statistically significant difference observed between total etch (T.E) i.e. Adper Single Bond 2 and self etch (S.E) i.e. P 90; caries affected dentin (CAD) and normal dentin (ND); with thermocycling and without thermocycling. (Refer Table 3)

For Adper Single Bond 2 (T.E), in normal dentin the mean values without thermocycling (28.8533) were higher compared to with thermocycling (25.4200). For the same in caries-affected dentin without thermocycling the mean values obtained were higher (20.5600) compared to with thermocycling (17.1667). Without thermocycling, T.E showed higher mean values obtained in normal dentin (28.85) than caries-affected dentin (20.56). With thermocycling, T.E showed higher mean values obtained in normal dentin (25.42) than caries-affected dentin (17.16). Statistically significant difference was seen, without thermocycling and with thermocycling ['p' value-0.001].

For, P90 (self-etch), in normal dentin the mean values without thermocycling (18.7333) were higher compared to with thermocycling (15.9467). For the same, in caries-affected dentin, without thermocycling the mean values obtained were higher (15.1067) compared to with thermocycling (12.0400). Statistically significant difference was seen, without thermocycling and with thermocycling ['p' value-0.001]. Without thermocycling, for S.E, the mean values for normal dentin (18.73 MPa) was higher than caries affected dentin, for $(15.10 \mathrm{MPa})$. For normal dentin, without thermocycling total etch (T.E) i.e. Adper Single Bond 2 (28.85) showed higher mean values compared with self etch (S.E) i.e. P90 (18.57). (Refer Graph 1)

For caries-affected dentin, without thermocycling, total etch, Adper Single Bond 2 (20.56 MPa) showed higher mean values than self-etch, P90 bonding agent $(15.10 \mathrm{MPa})$. For caries-affected dentin, without thermocycling, total etch, Adper Single Bond 2 (20.56 MPa) showed higher mean values than self-etch, P90 bonding agent $(15.10 \mathrm{MPa})$. Statistically significant results were also ob

Table 3: Statistical analysis using the students $\mathrm{T}$ test for independent samples and group samples. It was seen that for Adper Single Bond 2(T.E), in ND the mean values without thermocycling (28.8533) were higher compared to with thermocycling (25.4200). Also in case of CAD without thermocycling the mean values obtained were higher (20.5600) compared to with thermocycling (17.1667). Similarly, in case of P90 (S.E), in ND the mean values without thermocycling (18.7333) were higher compared to with thermocycling (15.9467).

\begin{tabular}{|c|c|c|c|c|}
\hline Class & N & Mean & Std. Deviation & Std. Error Mean \\
\hline TE_ND_WITHOUT & 15 & 28.8533 & 3.1412 & .8110 \\
\hline TE_ND_WITH & 15 & 25.4200 & 1.9266 & .4974 \\
\hline TE_CAD_WITHOUT & 15 & 20.5600 & 2.4882 & .6425 \\
\hline TE_CAD_WITH & 15 & 17.1667 & 1.6369 & .6425 \\
\hline TE_ND_WITHOUT & 15 & 28.8533 & 3.1412 & .8110 \\
\hline TE_CAD_WITHOUT & 15 & 20.5600 & 2.4882 & .6425 \\
\hline TE_ND_WITH & 15 & 25.4200 & 1.9266 & .4974 \\
\hline TE_CAD_WITH & 15 & 17.1667 & 1.6369 & .4227 \\
\hline SE_ND_WITHOUT & 15 & 18.7333 & 1.5490 & .4000 \\
\hline
\end{tabular}




\begin{tabular}{|c|c|c|c|c|}
\hline SE_ND_WITH & 15 & 15.9467 & 1.7671 & .4563 \\
\hline SE_CAD_WITHOUT & 15 & 15.1067 & 1.177 & .2886 \\
\hline SE_CAD_WITH & 15 & 12.0400 & 2.0986 & .5418 \\
\hline SE_ND_WITHOUT & 15 & 15.1067 & 1.1177 & .2886 \\
\hline SE_CAD_WITH & 15 & 12.0400 & 2.0986 & .5418 \\
\hline SE_ND_WITHOUT & 15 & 18.7333 & 1.5490 & .4000 \\
\hline SE_CAD_WITHOUT & 15 & 15.1067 & 1.1177 & .2886 \\
\hline SE_ND_WITH & 15 & 15.9467 & 1.7671 & .4563 \\
\hline SE_CAD_WITH & 15 & 12.0400 & 2.0986 & .5418 \\
\hline TE_ND_WITHOUT & 15 & 28.8533 & 3.1412 & .8110 \\
\hline SE_ND_WITHOUT & 15 & 18.7333 & 1.5490 & .4000 \\
\hline TE_CAD_WITHOUT & 15 & 20.5600 & 2.4882 & .6425 \\
\hline SE_CAD_WITHOUT & 15 & 15.1067 & 1.1177 & .2886 \\
\hline TE_CAD_WITH & 15 & 17.1667 & 1.6369 & .4227 \\
\hline SE_CAD_WITH & 15 & 12.0400 & 2.0986 & .5418 \\
\hline
\end{tabular}

Tained $(p<.000)$.

For caries-affected dentin, with thermocycling, total etch, Adper Single Bond 2 (17.16MPa) showed higher mean values than self-etch, P90 bonding agent (12.04 MPa). Statistically significant results were also obtained $(p<.000)$ (Refer Graph 2) Also, in case of caries-affected dentin without thermocycling the mean values obtained were higher (15.1067) compared to with thermocycling (12.0400)

\section{Discussion and Review of Literature}

The achievement of high-strength, durable bonds between tooth structure and restorative materials have been a longterm goal of the dental profession. The formation of such bonds would give way to a more conservative, adhesive and esthetic manner of dealing with tooth repair and the universal application of minimally invasive dentistry. Although bond strength testing is done on normal dentin for convenience, clinically most bonding substrates are not in normal dentin, but are in caries affected or sclerotic cervical dentin ${ }^{[15,16,18]}$. Hence, it has been used in comparison with normal dentin in the present study.
However, the structural variations in caries affected dentin may be a challenge to provide effective bonds. ${ }^{16}$ Lasting adhesion or the bond strength is the response of an assembly (e.g.: composite-tooth interface) to deformation loads. The development of new adhesive systems aims to create strong adhesion to all types of tooth substrate, particularly caries affected dentin ${ }^{[15]}$.

When stress is applied to the assembly, energy is absorbed by the adhesive and transferred and distributed to the components of the joint. Failure of such assemblies occurs as a result of flaws, which propagate under stress as cracks and can originate in any component of the assembly ${ }^{[9]}$.

The microtensile bond test was introduced by Sano et al. (Nakajima et al. 1995, Yoshima et al. 1996) and developed to overcome this problem by designing samples to concentrate stress to the bond layer of an assembly $[13,20,21]$. This method has several advantages over other testing methods such as resulting in fewer cohesive failures and producing far more adhesive failures $[2,7,11,13,21]$.

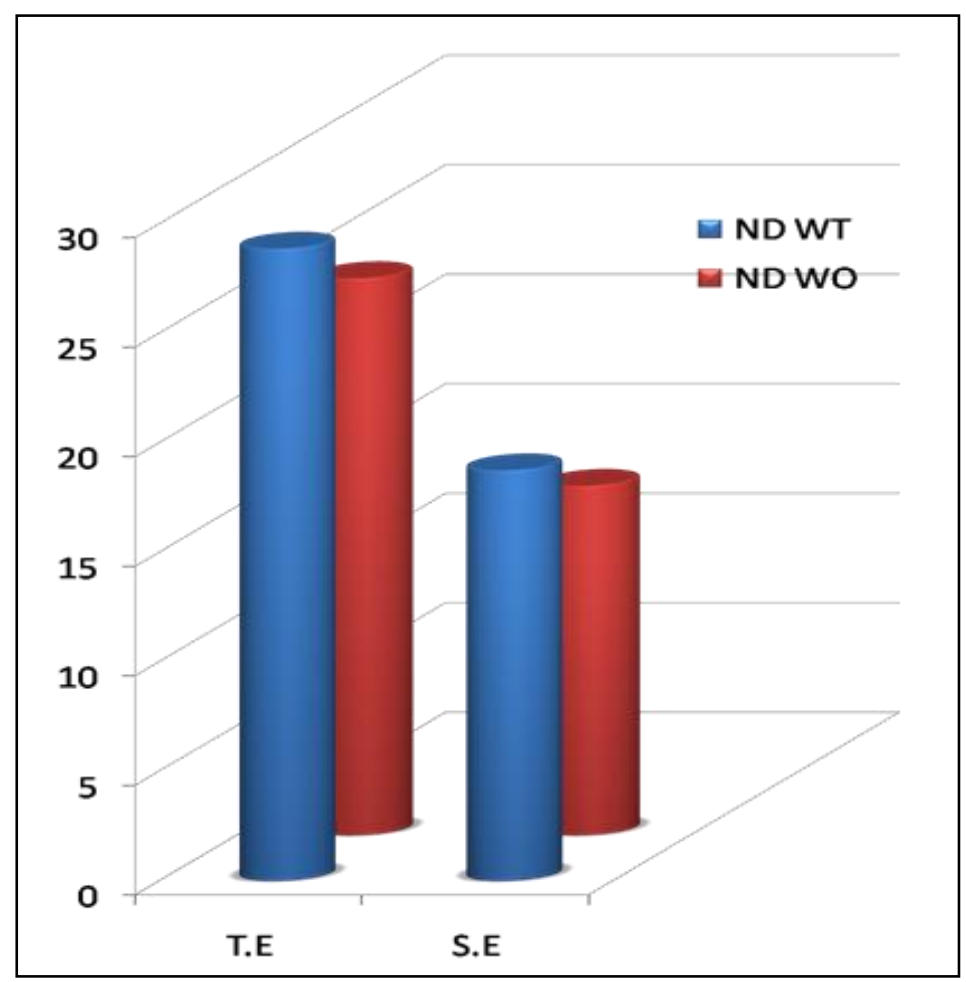

Graph 1: Comparison of Total Etch (Adper Single Bond 2) \& S.E (P90) with Normal Dentin (ND) before and after thermocycling. The graph depicts T.E having higher value than S.E for ND while overall value of T.E are higher than S.E for both groups 


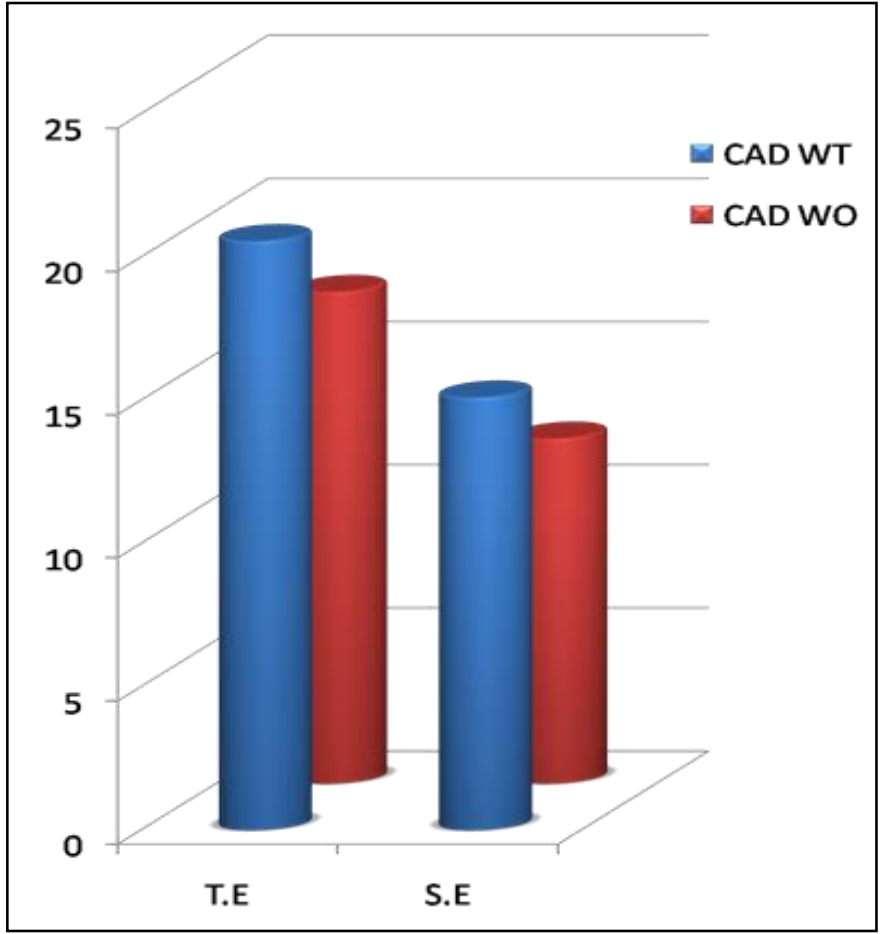

Graph 2: Comparison of Total Etch (Adper Single Bond 2) \& S.E (P90) with (CAD) caries - affected dentin before and after thermocycling. The graph depicts T.E having higher value than S.E for CAD while overall value of T.E are higher than S.E for both groups

It also permits appropriate sample size management by the use of only one tooth to fabricate several bonded dentin-resin rods i.e. the number of experimental units (tooth-composite assemblies) ${ }^{[9,14,20]}$. Each microtensile specimen is interpreted as a separate experimental unit, regardless of whether it is obtained from the same or different teeth.22 This provides better reliability of conclusions drawn from the vast literature on adhesives $[9,14,20]$

It allows testing of substrates of clinical significance, such as carious dentin, cervical dentin, and enamel.14,20 This technique also permits a more uniform stress distribution along the interface between dentin and resin during testing. ${ }^{11}$ Thus, information about the strength inherent to bonding materials (i.e. adhesives) rather than the adherends (or tooth structure) is generated.

There are also some disadvantages associated with the microtensile test. It is more cumbersome and more difficult to undertake than some of the conventional tests. However, the insights gained are thought to outweigh this issues ${ }^{[9]}$.

Dentin adhesives tend to function well in bond strength tests when tested shortly after application ${ }^{[3]}$. Clinically, the oral environment, with its moisture, physical stresses, changes in temperature and $\mathrm{pH}$, dietary components, and even chewing habits, considerably influences interactions between materials and tooth tissues [Gwinnett, 1990] ${ }^{[3,10]}$. Although thermal cycling represents only one of these challenges, the other factors may have a detrimental effect on the microtensile bond strength ${ }^{[3]}$.

In our study, the average mean values for Group I (total-etch, Adper Single Bond $2=17-28 \mathrm{MPa}$ ) had higher bond strength compared to Group II (self etching primer, P90 $=12-18$ $\mathrm{MPa})$

In case of total-etch system, as the demineralised collagen fibril mesh is used as the bonding substrate, a wet bonding technique is required to ensure its full expansion. The ethanol solvent of Single Bond, due to its high vapour pressure, competes with moisture, replacing it and promoting infiltration of monomer through the nano-spaces of the exposed collagen network. This serves as a mesh-work for the creation of a resin-demineralized dentin hybrid layer, resulting in a strong micromechanical interlocking between resin and the superficially demineralized dentin. This could probably account for the higher bond strength values showed by Single Bond compared to other groups [20]. This is supported by studies done by Neelima et al. and Yesilurt et al. who found that though the bond strength of AdheSE and Fuji Bond LC was above $30 \mathrm{Mpa}$, it was less than Single Bond as evaluated by testing of microtensile bond strength ${ }^{[20]}$.

The same results were confirmed by Kwong et al., Say EC et $a l$, etc who found that regardless of the conditioning methods, bond strengths to ND were significantly higher than CAD [11, 16, 17, 29].

Maria Carolina et al. supported the above results and also found that when bonded to caries-affected dentin, Single Bond had the highest bond strength, followed by Clearfil SE (self etching primer) ${ }^{[15]}$. Thus in CAD, the total etch adhesives preformed better than self-etch systems ${ }^{[4,16]}$. The reason for this seems that caries-affected dentin contains dentinal tubules that are filled with acid-resistant whitlockite minerals that interfere with the infiltration of adhesive reins and the formation of resin tags. The presence of these deposits in the dentinal tubules reduces dentinal permeability to near zero ${ }^{[4]}$. The decrease in modulus of elasticity is also a contributing factor ${ }^{[16,17]}$.

CAD presents lower nanomechanical properties and a lower cohesive strength. Knoop hardness testing of CAD is shown to be half of that of normal dentin. This is because they are dependent on the properties of the intertubular dentin, which is partially demineralised and more porous. The porous nature allows deeper penetration of monomers reflecting in thicker hybrid layers. However the bond strength is unrelated to the hybrid layers. Thus the weakest link is the resin-cariesaffected dentin assembly, probably due to the cohesive nature of the CAD ${ }^{[4,16,18]}$.

Gwinnett reported that resin infiltration accounted for about one third of the bond strength in acid-etched, sound dentin that was devoid of surface diffusion barriers ${ }^{[11]}$.

The application of $37 \%$ phosphoric acid, in total-etch, seems to solubilize the intratubular mineral deposits in $\mathrm{CAD}$, better than the weaker acids used in self-etching primers, thereby contributing to better resin retention. Thus the milder acids of the self-etch primers are not acidic enough to dissolve the mineral casts ${ }^{[4,11]}$. Also; bacteria entrapment within the resin layer may introduce defects that weaken the ultimate strength of the polymerized adhesive ${ }^{[11]}$.

Also in our study, we found that thermocycling reduced the bond strength further of total-etch and self-etch. Bond strengths of CAD were reduced more than ND. This result is supported by authors such as Jan De Munck et al. and Maria Carolina G Erhardt et al. ${ }^{[15,30]}$.

Thermocycling is a widely used artificial aging methodology. The ISO TR 11450 standard indicates that a thermocycling regimen comprising 500 cycles in water between 5 and 55 degree Celsius is an appropriate artificial aging test.

The artificial aging effect induced by thermocycling can be 2fold i.e. hot water may accelerate hydrolysis of non-protected collagen and extract poorly polymerized resin polymers and due to higher contraction/expansion coefficient of the restorative material (as compared to tooth tissue) repetitive contraction/expansion stresses are generated at toothbiomaterial interface resulting in cracks that may propagate 
along the bonded interfaces, causing gaps and inwards and outflow of pathogenic fluids called percolation. ${ }^{29}$

CAD bonds are more prone to hydrolytic degradation than ND bonds. According to Wang et al., the most influential character for void formation in CAD is its morphology and environment than increase water content. Even if no water is present during polymerization, environmental water can enter the polymer bulk and trigger chemical polymer degradation. Resin breakdown from hydrolytically unstable polymeric hydrogels within the hybrid layers of CAD may have continued to occur through the nanoleakage channels during aging ${ }^{[15]}$.

In vitro studies such as the present one, provides an idea of the strength and durability of bond strengths achieved with commonly available dentin bonding agents. However, more clinical research is needed in order to gain insight and further improvise on the present bonding concepts.

\section{Conclusion}

From the present study it can be concluded that

1. Adper Single Bond 2(total-etch) had higher bond strength values than P90 (self-etch) in normal dentin as well as caries-affected dentin.

2. Normal dentin showed higher bond strength values compared to caries-affected dentin for both Adper Single Bond 2 and $\mathrm{P} 90$ bonding agents.

3. Thermocycling reduced the bond strength of normal dentin as well as caries-affected dentin to both, Adper Single Bond 2 and P90.

These results are obtained within the experimental conditions of the present study. Extrapolation to clinical practice merits further investigations to confirm the observed data. Such studies give us an insight to the durability and longevity of such restorations in the presence of the challenging biomechanics factors of the oral cavity.

\section{Acknowledgements}

I thank, Dr Heblikar, HOD, Mechanical Engineering Department, SDM Engineering College for the designing and use of the thermocycling facility. I also thank Nettur Technology and Tools Fabrication Institute, Dharwad for manufacturing the jig to hold the samples. I thank $\mathrm{Mr}$ Vinayak Ogle, Innovation centre, 3M Labs, Bengaluru for the use of their facility and Instron, universal testing machine to conduct the micro tensile bond strength testing.

I would like to claim no benefits either commercial or financial by conducting this study. The study has been conducted in a pure unbiased manner.

\section{References}

1. Yoo HM, Pereira PNR; Effect of Blood Contamination with 1-step Self-etching Adhesives on Microtensile Bond Strength to Dentin; Operative Dentistry 2006;31(6):660665.

2. Tanumiharja M, Buffowa MF, Tyas MJ. Microtensile bond strengths of seven dentin adhesive systems; Dental Materials 2000;16:180-187.

3. Omar H, Badrawy Wei, El-Mowafy, et al. Microtensile Bond Strength of Resin Composite Bonded to Cariesaffected Dentin with Three Adhesives; Operative Dentistry 2007;32(1):24-30.

4. Ceballos Laura, Camejo Defren, FuentesVictoria M. Microtensile bond strength of Total-etch and self-etching adhesives to caries-affected dentine Journal of Dentistry
2003;31:469-477.

5. Pereira PNR, Nunes MF, Miguez PA, Swift EJ Jr; Bond Strengths of a 1-Step Self-etching System to Cariesaffected and Normal Dentin; Operative Dentistry 2006;31(6):677-681.

6. Armstrong Steven R, Boyer Daniel B, Keller John C. Microtensile bond strength Testing and failure analysis of two dentin adhesives; Dent Mater 1998;14:44-50.

7. Schreiner Rebecca F, Chappell Robert P, Glaros Alan G, et al. Microtensile Testing of dentin adhesives; Dent Mater 1998;14:194-201.

8. Phrukkanon Suwachai, Burrow Michael F, Tyas Martin. The influence of cross-Sectional shape and surface area on the microtensile bond test; Dent Mater 1998;14:212 221.

9. Stangel Ivan, Ellis Thomas H, Sachen Edward. Adhesion to tooth structure mediated by contemporary bonding systems; Dent Clin N Am 2007;51:677-694.

10. Meerbeek Van et al. Adhesion to mineralized tissues; Operative Dentistry, Supplement 5, 111-24

11. Kwong SM, Cheung GS, Kei LH et al. Microtensile bond strengths to sclerotic Dentin using a self-etching and a total-etching technique; Dental Materials 2000;18:359369.

12. Knobloch LA, Gailey D, Azer S et al. Bond strengths of one- and two- step self etch adhesives; Journal of Prosthetic Dentistry 2007;97:216-22.

13. Sriruk Nakornchal, Choltacha Harnirattisai, Rudee Surarit. Microtensile bond strength of a total-etching vs. self-etching adhesive to caries affected and intact dentin in primary teeth; JADA 136(200):477-483.

14. Roberson Theodore M, Heymann Harold, Swift Edward Sturdevant's Art and Science of Operative Dentistry, $5^{\text {th }}$ Edition.

15. Sonoda H, Banerjee A, Sheriff M, Tagami J. An in vitro investigation of microtensile bond strengths of two dentine adhesives to caries- affected dentine; Journal of Dentistry 2005;33:335-42.

16. Erhardt Maria Carolina G, Toledano Manuel, Osorio Raquel. Histomorphologic Characterization and bond strength evaluation of caries-affected dentin/resininterfaces: Effects of long-term Water exposure; Dental Materials 2008;24:786-798.

17. Yashiyama M, Tay FR, Doi J, et al. Bonding of self-etch and total-etch adhesives to carious dentin; J Dent Res 2002;81(8):556-560.

18. Nakajima M, Sano H, Burrow MF, et al. Tensile bond strength and SEM evaluation of caries-affected dentin using dentin adhesives; J Dent Res 1995;74(10):1679-88.

19. Torres Carolina Paes, Silmara Aparecida Milori Corona, Renata Pereira Ramos, et al. Bond Strength of Selfetching Primer and Total-etch Adhesive Systems to Primary Dentin. J Dent Child 2004;71:131-134.

20. Neelima L, Sathish ES, Kandaswamy D et al. Evaluation of microtensile bond strength of total-etch, self-etch and glass ionomer adhesive to human dentin: an in vitro study; Indian J Dent Res 2008;19(2).

21. Yesilurt C, Bulucu B. Bond strength of total-etch and self-etch dentin adhesive systems on the peripheral and central dentinal tissues: A microtensile bond strength; The Journal Of Contemporary Dental Practice 2006;7(2).

22. Uekusa S, Yamaguchi K, Miyazaki M, Tsubota K et al. Bonding efficacy of single step self-etch systems to sound primary and permanent tooth dentin; Operative Dentistry 2006;31(5):569-76. 
23. Kerby RE, Knobloch LA, Clelland N, Lilley $H$. Microtensile Bond Strengths of OneStep and Self-etching Adhesive Systems; Operative Dentistry 2005;30(2)195200

24. Frankenberger R, Perdigão J, Rosa BT, et al. No-bottle vs. Multi-bottle dentin adhesives-A microtensile bond strength and morphological study; Dental Materials 2001; $17: 373-80$.

25. Esra Can Say, Masatoshi Nakajima, Pisol Senawongse; Microtensile bond Strength of a filled vs. unfilled adhesive to dentin using self-etch and total-etch technique; Journal of Dentistry 2006;34:283-291

26. De Silva Al, Lima DA, De Souza Gm. Influence of additional adhesive application on the microtensile bond strength of adhesive systems; Oper Dent 2006;31(5):5628.

27. Molla K, Park HJ, Haller B. Bond strength of adhesive/composite combinations to dentin involving total- and self-etch adhesives; J Adhes Dent 2002;4(3):171-80.

28. Nikaido $\mathrm{T}$, Kunzelmann $\mathrm{KH}$, Ogata $\mathrm{M}$. The in vitro dentin bond strengths of two adhesive systems in class I cavities of human molars; J Adhes Dent 2002;4(1):31-9.

29. Say EC, Nakajima M, Senawongse P, Soyman M, et al. Bonding to sound vs.caries-affected dentin using photoand dual-cure adhesives; Oper Dent 2005;30(1):90-8.

30. De Munck J, Van Landuyt $\mathrm{K}$, Coutino E, et al. Microtensile bond strength of adhesives bonded to class I cavity-bottom dentin after thermocycling; Dental Materials 2005;21:999-1007.

31. Armstrong SR, Vargas MA, Fang Q. Microtensile bond strength of a total-etch 3-step, total-etch 2-step, self-etch 2-step, and a self-etch 1-step dentin bonding system through 15-month water storage; J Adhes Dent 2003;5(1):47-56.

32. Yazici AR, Akca T, Ozgünaltay G. Bond strength of a self adhesive system to caries affected dentin; Operative Dentistry 2004;29(2):176-81.

33. Waidyasekera PG, Nikaido T, Weerasinghe DD; Bonding of acid-etch and self-etch adhesives to human fluorosed dentin; Journal of Dentistry 2007;35:915-22.

34. Proeñça Jatyr P, Polido Mario", Osorio Estrella et al.; Dentin regional bond strength of self-etch and total-etch adhesive systems; Dental Materials 2007;23:1542-548.

35. Nikaido T, Kunzelmann K.H, Chen H, et al. Evaluation of thermal and mechanical loading on bond strength of a self-etching primer system to dentin; Dental Materials 2002;18:269-275.

36. Armstrong Steven R, Boyer Daniel B, Keller John C. Microtensile bond strength testing and failure analysis of two dentin adhesives; Dent Mater 1998;14:44-50.

37. Cardoso Paulo EC, Braga Roberto R, Carrilho Marcela RO. Evaluation of micro-tensile, shear and tensile tests determining the bond strength of three adhesive systems; Dent Mater 1998;14:394-398.

38. Hidehiko Sano, Tsunekazu Shono, Hidekazu Sonoda. Relationship between surface area for adhesion and tensile bond strength - Evaluation of a micro-tensile bond test; Dent Mater 1994;10:236-240.

39. Cehreli Zafer C, A Yazici Ruya, Akca Taner. A morphological and micro-tensile bond strength evaluation of a single-bottle adhesive to caries-affected human dentine after four caries removal techniques; Journal of Dentistry 2003;31:429-435.

40. ALF Silva, DANL Lima, GMD Souza, CTD Santos.
Influence of Additional Adhesive Application on the Microtensile Bond Strength of Adhesive Systems; Operative Dentistry 2006;31(5)562-568.

41. Ghassemieh Elaheh. Evaluation of source of uncertainities in microtensile bond strength of dental adhesive system for different specimen geometries; Dental Materials 2008;24:536-547.

42. Karakaya S, Unlu N, Say EC, Ozer F, Soyman M, Tagami $\mathrm{J}$ et al. Bond strengths of three different dentin adhesive systems to sclerotic dentin; Dent Mater J 2008;27(3):471-9.

43. Armstrong SR, Vargas MA, Fang Q, Laffoon JE. Microtensile bond strength of a total-etch 3-step, totaletch 2-step, self-etch 2-step, and a self-etch 1-step dentin bonding system through 15-month water storage; J Adhes Dent 2003;5 (1): 47-56.

44. Lodovici E, Reis A, Geraldeli S, Ferracane JL, Ballester $\mathrm{RY}$, et al. Does adhesive thickness affects resin-dentin bond strength after thermal/load cycling? Oper Dent 2009;34(1):58-64.

45. Yoshiyama M, Urayama A, Kimochi T, Matsuo T, Pashley DH. Comparison of conventional vs. self-etching adhesive bonds to caries-affected dentin; Oper Dent 2000;25(3):163-9.

46. Soares FZ, Rocha Rde O, Raggio DP, Sadek FT, Cardoso PE. Microtensile bond strength of different adhesive systems to primary and permanent dentin; Pediatr Dent 2005;27(6):457-62. 